\title{
REPRESENTAÇÕES DO SERVIÇO DOMÉSTICO NA FICÇÃO TELEVISIVA: NOTAS SOBRE CONSUMO E DIFERENÇA SOCIAL
}

\author{
REPRESENTATIONS OF DOMESTIC SERVICE IN TELEVISION FICTION: \\ NOTES ON CONSUMPTION AND SOCIAL DIFFERENCE
}

\author{
REPRESENTACIONES DEL SERVICIO DOMÉSTICO EN LA FICCIÓN \\ TELEVISIVA: \\ NOTAS SOBRE CONSUMO Y DIFERENCIA SOCIAL
}

Carla Barros

Universidade Federal Fluminense barros.carla@uol.com.br

\begin{abstract}
Resumo
Este artigo se propõe a analisar representações do serviço doméstico presentes em determinados programas ficcionais televisivos - se detendo, em especial, no seriado $A$ Diarista da TV Globo - procurando identificar de que modo diferenças entre classes são concebidas. Trata-se de investigar como os personagens são apresentados como "representantes" de um determinado estilo de vida "popular", em contraponto ao universo dos "ricos". O consumo surge, no universo estudado, como um elemento de distinção de classe, se configurando como um grande sistema classificatório. A partir da análise de representações do emprego doméstico, que inclui uma discussão final em torno das novelas Avenida Brasil e Cheias de Charme, o estudo procura relacionar algumas interpretações sobre os confrontos entre classes com os caminhos da mobilidade social no contexto brasileiro.
\end{abstract}

Palavras-chave: Consumo. Empregada Doméstica. Televisão.

\begin{abstract}
This paper intends to analyze representations of housework service present in certain fictional television programs - focusing, in particular, the Globo TV series A diarista - trying to identify how differences between classes are constructed. The article explores how the characters are presented as "representatives" of a certain "popular" lifestyle as opposed to the universe of the "rich". Consumption emerges, here, as a element of class distinction, shaping up as a great classificatory system. From the analysis of representations of domestic employment, which includes a final discussion about the soap operas Avenida Brasil and Cheias de Charme, the study seeks to relate some interpretations of clashes between classes with the paths of social mobility in the Brazilian context.
\end{abstract}

Keywords: Consumption. Housemaids. Television. 


\section{Resumen}

Este artículo tiene como objetivo analizar las representaciones sobre el servicio doméstico en algunas obras de ficción televisiva - deteniéndose, especialmente, en la serie A Diarista de la TV Globo - tratando de identificar cómo las diferencias entre las clases están diseñadas. Se está investigando cómo los personajes se presentan como "representantes" de un cierto estilo de vida "popular", en contraposición al universo de los "ricos". El consumo surge en el universo estudiado como un elemento de distinción de clases, constituyéndose em un amplio sistema de clasificación. A partir del análisis de las representaciones sobre el servicio doméstico, que incluye una discusión final sobre las telenovelas Avenida Brasil e Cheias de Charme, el estudio busca relacionar algunas interpretaciones de los enfrentamientos entre las clases con los caminos de la movilidad social en el contexto brasileño.

Palavras-chave: Consumo. Criada. Televisión.

\section{Introdução}

O presente artigo se propõe a realizar uma análise das relações de consumo expressas no seriado A Diarista, exibido pela TV Globo entre os anos de 2004 e 2007, contrapondo-o a outras produções que apresentam importantes personagens no papel de "domésticas". Para tanto, será retomada (BARROS, 2007) uma investigação sobre as representações relativas aos diferentes universos sociais que aparecem no seriado - mais especificamente, o dos "pobres" e o dos "ricos" - onde a dimensão do consumo surge como meio privilegiado de expressão de diferenças sociais. Após a análise mais detalhada do seriado, algumas reflexões serão feitas sobre o "protagonismo" do serviço doméstico em recentes produções da ficção televisiva nacional, a saber, as novelas Cheias de Charme e Avenida Brasil, também produções da TV Globo.

Douglas e Isherwood (2004), em um trabalho clássico no campo dos estudos do consumo, chamavam atenção para a capacidade deste fenômeno de "dar sentido" ao universo cotidiano: "O consumo usa os bens para tornar firme e visível um conjunto particular de julgamentos nos processos fluidos de classificar pessoas e eventos" (p.115). O campo de estudos de consumo veio se constituindo a partir daí com a contribuição de diversos autores entre os quais, Colin Campbell (2001) e Daniel Miller (2010) - que procuraram retirar este fenômeno da posição de mero reflexo da produção, colocando-o em um lugar central de análise, capaz de produzir um discurso sobre as relações sociais. Abandonava-se assim, uma visão utilitária do consumo, que prevalecia no viés economicista, passando a se dar a devida 
atenção ao seu significado cultural, suas práticas e seus sentidos públicos, em contraposição às explicações centradas no plano do indivíduo.

$\mathrm{O}$ artigo se insere, assim, em uma perspectiva de diálogo entre as áreas de antropologia do consumo e comunicação, procurando, ainda, relacionar a produção televisiva escolhida ao seu contexto sócio-cultural mais amplo, promovendo um contraponto entre a obra ficcional e o material resultante de uma etnografia realizada pela autora, voltada para a compreensão do consumo de empregadas domésticas (BARROS, 2007). Neste estudo, a mídia televisiva apareceu como peça importante no encontro entre dois mundos - o da patroa e o da empregada.

Conforme já argumentou Gomes (1998), a telenovela pode, até certo ponto, ser analisada como um mito, por apresentar uma visão "totalizante" da realidade:

O que significa dizer, mais uma vez, que na telenovela brasileira não existe problema impossível de ser 'formulado' e equacionado, uma vez que ela apresenta um modelo completo e holístico de sociedade, no qual tudo se encontra encaixado (hierarquizado) e tem o seu lugar (GOMES, 1998: p.25).

A autora propõe, na verdade, que a novela seja percebida como um produto que se situaria entre o discurso mítico e o histórico, por ter uma ambição totalitária por um lado, e, por outro, incorporar o tempo e a mudança.

Partindo da ideia de que o seriado A diarista também possa ser analisado em seus aspectos míticos, no sentido de podermos encontrar ali um modelo holístico e "estável" de sociedade, onde as partes se encaixam de modo hierárquico (DUMONT, 1972), o desafio da análise recai, inicialmente, sobre o reconhecimento das representações sobre os universos sociais que se confrontam na trama e os modos possíveis de reconhecimento e relacionamento com o mundo do Outro.

Cabe aqui indicar o que está se entendendo como "modo hierárquico". Louis Dumont (1972) argumenta que a noção de indivíduo é o princípio estruturador da ideologia moderna, em que as partes (indivíduos) prevalecem sobre o todo (sociedade). Na sociedade moderna, o indivíduo é concebido como o valor supremo, definido como um ser autônomo, livre das amarras sociais. A este modelo Dumont contrapõe a noção de hierarquia, em que o todo tem sempre precedência sobre as partes. Aqui, a identidade das pessoas se constitui a partir de uma série de relações pré-definidas pela totalidade social, em que um termo da relação tem 
primazia sobre o outro - homem sobre mulher, velhos sobre novos, e assim por diante. No esquema hierárquico, a determinação de valores está fundamentalmente em esferas localizadas fora do indivíduo, como a religião, a família, a comunidade e a tradição. A hierarquia estudada por Dumont aparece em sua obra não apenas como uma propriedade do sistema de castas da Índia, mas como um princípio de classificação presente em qualquer sociedade. Hierarquia, nesta concepção, implica em complementaridade entre as partes, ou seja, em relações não-igualitárias onde as diferenças se encontram naturalizadas.

Antes da análise proposta referente a representações sobre universos distintos no seriado A Diarista, segue um rápido levantamento, para não fugir ao escopo do artigo, da figura da empregada doméstica na teledramaturgia brasileira.

\section{Empregadas na TV: um breve panorama}

A presença das empregadas domésticas na televisão brasileira foi analisada por Rezende (1997), em um trabalho onde a autora discutiu duas imagens que se afastavam das habituais representações dessa profissão nos produtos ficcionais televisivos, por terem traços marcantes em personagens bem desenvolvidas dentro da trama e por não serem negras, como de hábito: a de Edileuza, do programa humorístico Sai de Baixo, empregada que se impunha com uma enorme autoridade frente a seus patrões e a de Sexta-feira, da novela Salsa $e$ Merengue, caracterizada por sua fidelidade à patroa e também por seu "exotismo", contrastado aos gestos "civilizados" desta última. A autora estende sua investigação às representações de empregadas presentes nas novelas $A$ Indomada e $O$ Rei do Gado ${ }^{1}$, mostrando que, por um lado, existe uma constante afirmação das empregadas como pessoas "diferentes" dos patrões, caracterizadas de "pobres", "ignorantes", "bregas" e "supersticiosas" (p. 87); por outro, as personagens remetem a uma visão clássica da relação de lealdade e intimidade com quem as emprega, remetendo à obra de Freyre (1987). As relações afetivas entre empregadas e patrões, segundo Rezende, articulam as diferenças entre os dois lados,

\footnotetext{
${ }^{1}$ As novelas analisadas por Rezende (1997), assim como o programa humorístico Sai da Baixo, são produções da TV Globo.
} 
podendo variar da intimidade sexual à amizade e amor fraternal, incluindo também a possibilidade de a proximidade ser vivida como ambígua e perigosa.

A erotização da relação entre patrão e empregada é um dos temas recorrentes da teledramaturgia, tendo tido uma versão mais inusitada na novela da TV Globo Mulheres Apaixonadas, exibida em 2003, onde uma patroa de classe média alta mostra um grande interesse pelo universo sexual da empregada, o que a faz trair o marido com o namorado taxista desta última, além de vestir o uniforme de sua subalterna em um momento de fetichismo. A troca de papéis entre empregada e patroa também já foi tematizada na novela Cobras e Lagartos, veiculada pela TV Globo no ano de 2006, onde uma personagem de empregada torna-se a "dona da casa" no meio da trama, assumindo, em tom de vingança, o autoritarismo e a arrogância de sua até então patroa, que passa a servi-la.

Um outro papel de doméstica marcante na teledramaturgia foi o vivido pela atriz Camila Pitanga na novela Belíssima, veiculada pela TV Globo nos anos de 2005 e 2006 . O que chamou atenção na época, curiosamente, foram os uniformes usados pela personagem, considerados coloridos, fashion, se distanciando assim dos modelos tradicionais. O programa Fantástico $^{2}$ da TV Globo, apresentou uma reportagem sobre este "sucesso", mostrando empregadas que reclamavam dos uniformes antigos, elogiavam os modelos usados pela atriz na novela e davam sugestões para novas versões, como sem alças, mais curtos, etc. A matéria terminava com estilistas mostrando a "tendência" de mercado na direção de uniformes de empregadas ao estilo "Camila". Na novela, a personagem acabou cumprindo uma trajetória de ascensão social, deixando de ser doméstica e casando-se ao final com um dos "mocinhos" da trama.

Algumas imagens saídas das páginas de Casa Grande \& Senzala (FREYRE, 1987) parecem ter sido fonte de inspiração para parte das representações sobre a empregada doméstica presentes em telenovelas, como uma derivação do erotismo das mucamas com os jovens senhores no período colonial. Como constantes ameaças infiltradas no universo da casa, as empregadas podiam em alguns casos reverter a situação, se tornando patroas. Outra possibilidade ficcional mostrou a reafirmação da diferença entre patrões e empregados, em

\footnotetext{
${ }^{2}$ Programa exibido no dia 26 de março de 2006.
} 
que a condição de doméstica, como pessoa "pobre", está presa à imutabilidade e complementaridade das relações sociais hierárquicas.

O emprego doméstico ganha, por fim, um lugar de "protagonismo" com a série $A$ Diarista, que será analisada mais detalhadamente a seguir.

\section{A Diarista: consumo e punição no confronto entre dois mundos}

O seriado A Diarista, exibido pela TV Globo de abril de 2004 a julho de 2007 ao longo de quatro temporadas ${ }^{3}$, figura ao lado de outras produções que passaram a apresentar histórias desenvolvidas em ambientes de classes populares, como Cidade dos Homens, seriado da mesma TV Globo exibido entre os anos de 2002 e 2005, e Vidas Opostas, novela veiculada na TV Record em 2006 e 2007, ambas com enredos que se passam no cotidiano de favelas cariocas. No seriado A Diarista, as tramas têm como cenário principal o emprego doméstico e envolvem Marinete, a diarista-personagem título. Chama atenção, inicialmente, que em um seriado com uma protagonista pertencente às camadas populares, a dimensão do trabalho seja central para o desencadeamento das tramas - as histórias são desenvolvidas, em geral, a partir de situações que ocorrem no "serviço" de Marinete, em especial da interação entre a diarista e seus patrões, que mudam a cada episódio. O universo popular por onde Marinete circula também tem destaque nas histórias, sendo formado pelas amigas Dalila (vizinha e "mãe de santo"), Ipanema (trabalha como bombeira e se veste de modo masculinizado) e Solineuza (melhor amiga, sujeita a chacotas da parte de Marinete devido à sua enorme "burrice"). O dono da agência de empregadas, seu Figueirinha, completa a lista dos personagens fixos do seriado.

Ao fazer um breve comentário sobre o seriado em um trabalho anterior (BARROS, 2007), já havia ressaltado que uma das marcas do programa era a recorrente afirmação da diferença entre "pobres" e "ricos" - uma série de bordões eram ditos pela protagonista durante os episódios, destacando as características e a imutabilidade de cada uma daquelas condições sociais, em especial a da pobreza, entre eles: "pobre sempre anda com a carteira

\footnotetext{
3 Em 2011 estava previsto o retorno do seriado à grade da emissora; no entanto, as gravações foram interrompidas, conforme divulgado na época pela imprensa, devido a problemas de saúde da atriz Claudia Rodrigues, protagonista do programa.
} 
profissional na bolsa", "ouvido de pobre não escolhe o que ouve", "fruto do mar de pobre é banana d'água“, "pobre só vai pra frente quando a polícia corre atrás", "em tempos de saci, uma calça dá pra dois" e "bêbada rica é divertida, bêbada pobre é pervertida". Concluindo o comentário, observava que todas as vezes que a diarista vivia alguma situação de possibilidade de mudança do seu lugar social, os resultados eram catastróficos, levando a um retorno e à conformidade com o papel de subordinada ao final.

Em uma passagem emblemática de uma edição do programa ${ }^{4}$, Marinete chora copiosamente ao ver uma propaganda de margarina, dizendo que aquela cena nunca iria acontecer com ela - na peça publicitária, um homem oferece à sua mulher uma fatia de pão com margarina, em um clima de felicidade extrema, tendo como cenário uma cozinha de classe alta, ampla e bastante iluminada pela luz do sol. O "sonhar acordado" provocado pela propaganda (ROCHA, 1985; CAMPBELL, 2001) está interditado para a diarista, que não poderá viver a transformação promovida pelo produto, porque o seu lugar - como "pobre" não será mudado, por mais que tente.

Seu papel nas tramas é, muitas vezes, o de salvar os "ricos" de alguma situação crítica, embora em tantas outras ela provoque um grande caos nas casas onde trabalha. Nos moldes de uma relação hierárquica (DUMONT, 1972), os papéis são definidos de modo complementar cabe à diarista "pobre" cuidar e, eventualmente, "salvar" seus patrões, enquanto recebe em troca o pagamento em forma de "diária" e proteção.

Em um artigo elaborado com outros colegas ${ }^{5}$ (SUAREZ, MOTTA e BARROS, 2009), destacamos como a oposição de classes sociais ocupa um papel central na definição dos personagens e suas trajetórias no seriado. Esta oposição ("pobres" x "ricos") é traduzida no comportamento de consumo de Marinete e de seus patrões. Assim, o universo do consumo dos ricos é marcado pelo excesso, esbanjamento e fartura; o de Marinete e suas amigas, pelo signo da restrição e escassez. Em um dos episódios ${ }^{6}$, por exemplo, Marinete controla em sua casa o consumo de suco por Dalila, enquanto na casa dos patrões, ela reclama da quantidade de comida que precisa preparar: "parece que eles nasceram numa lanchonete!" O episódio

\footnotetext{
${ }^{4}$ Programa exibido no dia 19 de abril de 2005.

${ }^{5}$ As análises dos episódios apresentadas no artigo feito com colegas foram desenvolvidas por Maribel Suarez para um trabalho realizado no âmbito de uma disciplina ministrada pelo Prof. Paulo César Motta, no curso de Doutorado em Administração do IAG/PUC-Rio.

${ }^{6}$ Episódio: Aquele com os Adolescentes.
} 
também mostra o desperdício, já que os adolescentes jogam no lixo parte dos sanduíches preparados.

Para ilustrar a contraposição entre os dois universos, reproduzo aqui uma das análises ${ }^{7}$ :

\begin{abstract}
A oposição restrição (pobre) x excesso (ricos) também se evidencia quando Marinete idealiza a viagem que terá oportunidade de fazer ao exterior. Figueirinha, o dono da agência de empregos, pretende lhe remunerar com a passagem de ônibus. Sem outra opção de receber seu pagamento, ela aceita a proposta já que também se sente tentada pela possibilidade de viajar para fora do país. Em pensamento a diarista "viaja" para um paraíso imaginário, onde ela está deitada numa cadeira de praia, com chapéu, maiô e óculos escuros. A música de fundo é "Viva la vida loca", e um homem parecido com o cantor latino Rick Martin dança, enquanto ela bebe um drink de abacaxi e come frutas, com voracidade. A seguir, conversando com as amigas, esse "sonho de consumo" volta a se manifestar. No que poderia ser o quarto de um luxuoso motel, Marinete assiste à dança do belo "latino" e bebe champanhe com ansiedade: primeiro normalmente, depois do gargalo da garrafa, deixando transbordar pela boca, até que ela come a própria taça. Enquanto ele rebola, ela também se delicia com gelatina, lambuzando o corpo, no que promete ser uma noite de excessos. Numa cena a seguir, Solineuza comenta com Dalila: "Tu já imaginou a Nete no estrangeiro, dando uma de patrão e fazendo compras?" Assim, o processo de transformação de Marinete (do comportamento de empregada à patroa), concretizado na viagem ao exterior, parece reforçar a visão dos patrões como uma vida de esbanjamento, em contraposição às limitações que a doméstica vive no seu dia-a-dia. (SUAREZ, MOTTA E BARROS, 2009: p.214)
\end{abstract}

Neste e em outros episódios analisados no referido trabalho, alguns aspectos chamam atenção. Em especial, o lugar das práticas de consumo como definidoras de diferentes situações de classe e a dramatização da "mudança de lugar" da diarista, quando confrontada com a possibilidade de usufruir do "mundo dos ricos", seja como sonho ou "realidade". O seriado sugere que mesmo tendo a posse dos bens de outra classe, Marinete termina por revelar o seu lugar de origem. Ainda que consiga vencer a "barreira de entrada" para o consumo (por exemplo, adquirir o produto), a forma de consumir acaba por revelar que ela não pertence ao universo dos ricos. Trata-se do que Bordieu (1980) classificou como habitus e se relaciona ao fato de que uma pessoa pertencente a determinado grupo compartilhe gestos,

\footnotetext{
${ }^{7}$ Episódio: Aquele do Paraguai I. 
posturas, que têm no conjunto um poder modelador que acaba garantindo a homogeneização dos gostos dentro de um grupo social.

Outro ponto a ser destacado em A diarista é que a experimentação do consumo dos ricos não se dá a partir de uma escolha de Marinete, mas sim como fruto de acaso, revelando seu pouco controle das situações em que se observaria um deslocamento do personagem para uma experiência de outra classe social. Pensando de um modo relacional, o "consumo dos ricos" seria marcado pela escolha e excessos, enquanto o "consumo dos pobres" pela passividade e carência material. Ao tentar passar do seu universo social para o do outro através da mediação do consumo, a diarista experimenta uma série de infortúnios e humilhações, que a levam invariavelmente de volta ao seu mundo familiar.

Pode-se fazer aqui um contraponto com o trabalho de Machado e Vélez (2008) sobre a telenovela colombiana Yo Soy Betty la Fea, onde os autores mostram que o conflito básico apresentado na obra é instaurado entre "beleza" e "feiúra", sendo este último "...um conceito que tem menos a ver com atributos físicos do que com a estratificação dos papéis sociais numa sociedade de valores rigidamente cristalizados" (p.96). Ao analisar a originalidade do modelo trazido por essa novela, chamam atenção de como os aspectos físicos - e, portanto, visíveis dos personagens - são percebidos como correlacionados com o lugar ocupado dentro de um determinado universo social concebido, em um primeiro momento, como imutável. A novela acabaria, na verdade, por subverter e "desarrumar" esse sistema estável apresentado inicialmente, enquanto no seriado brasileiro se observa uma reafirmação da estrutura hierárquica que sustenta as relações entre pobres e ricos.

Em A diarista revela-se uma percepção dominante sobre o que seja o "mundo dos pobres" - existe aqui a ideia de que grupos populares viveriam em um mundo marcado pela lógica da falta, da sobrevivência e da carência material. Os recursos, sempre escassos, levariam a uma postura de passividade frente à vida e de sujeição a condições sociais adversas. Analisando especificamente os reflexos desta visão no campo do consumo, membros de camadas populares não seriam protagonistas porque não fariam escolhas - como já indicou Slater (2002), a possibilidade de escolha é fundamental na gênese do consumo moderno - mas responderiam a "necessidades básicas". Tais percepções encontram-se, de fato, bastante disseminadas na sociedade, tanto no campo do senso comum quanto em certos segmentos do meio acadêmico. Por um lado, pode-se perceber uma visão moralista sobre o 
consumo, que "condena" os pobres quando estes adquirem bens "supérfluos" do ponto de vista de quem acusa. Nessa concepção, os indivíduos de baixa renda deveriam se restringir ao mundo dos bens adequados ao seu status, marcado pela carência material e sem escolhas no campo do consumo. Um dos modelos produzidos pelo mundo acadêmico e que tem correspondência com tais pressupostos é o da "hierarquia de necessidades", criado nos anos 40 pelo psicólogo e Professor universitário norte-americano Abraham Maslow.

A "pirâmide de Maslow" propõe que o comportamento humano possa ser explicado a partir do entendimento de uma hierarquia de necessidades universais, que compreenderia cinco categorias distintas, das mais "básicas" às mais complexas: necessidades fisiológicas, de segurança, de participação e afeição, de estima e de auto-realização. Estas necessidades estariam organizadas de forma hierárquica, pois se manifestariam no ser humano a medida que um estágio anterior fosse satisfeito (MASLOW, 1954). Existiram "necessidades mais básicas", que estariam na base da pirâmide, tais como fome, sede, sono e sexo - os indivíduos nesse plano seguiriam seus instintos, consumindo para saciar suas necessidades de sobrevivência e não teriam novas motivações até que esse estágio fosse satisfeito.

Modelos como o da "Pirâmide de Maslow", que atualizam a lógica da carência material, podem ser refutados quando se considera que precariedade de recursos materiais não significa precariedade simbólica. O ser humano se caracteriza enquanto tal por estar imerso na cultura, que não pode ser entendida como um simples agregado de traços culturais. Sua característica distintiva é exatamente o fato de viver segundo uma lógica simbólica, e não prática, como mostrou Sahlins (1979), entre outros. O fato de que alguns grupos tenham mais dificuldades de sobrevivência material não implica que sejam movidos segundo uma lógica prática, de sobrevivência, o que, se fosse verdade, inclusive, faria deles menos humanos do que os outros.

Pensando no campo das ciências sociais brasileiras sobre os modos de vida da classe trabalhadora, vale ressaltar que até os anos 80, a maioria desses estudos - inventariados de forma abrangente por Sarti (1996) - definia tais segmentos essencialmente a partir de suas relações de trabalho. Tanto em abordagens marxistas quanto nos trabalhos que pesquisavam as "estratégias de sobrevivência" da base da pirâmide, o foco de análise recaia sobre os mecanismos que as famílias estudadas usavam para garantir sua "sobrevivência material". Como destacou Sarti (1996, p.17), a dimensão simbólica não encontrava espaço nesse tipo de 
análise, pois tudo parecia ser movido graças a uma "razão prática" que permitia às pessoas sobreviverem em um ambiente de grande escassez material. Tratava-se de uma verdadeira lógica da "falta", seja de bens, de trabalho ou de "consciência de classe". Somente a partir dos anos 80 o quadro se reverte, em especial, com o surgimento de vários estudos etnográficos abordando temas como o cotidiano e relações de família e gênero. Estes estudos passaram, assim, a enfatizar o modo de vida e as representações sociais de segmentos de trabalhadores pobres urbanos, mostrando como é a dimensão cultural que, de fato, instaura a vida em sociedade. O foco na "falta" acaba por encobrir o simbolismo que organiza e cria sentido para a vida de qualquer grupo social (SAHLINS, 1979).

\section{Televisão, consumo e mediação}

Procurando analisar de que modo são representados diferentes universos sociais e suas relações em A Diarista e sabendo que o "outro" pobre é uma construção do seriado, e não um dado natural, alguns aspectos merecem atenção. Em primeiro lugar, o modo como a dimensão do consumo aparece como meio privilegiado na definição do que seja o universo de pobres e ricos. O "mundo dos bens" (DOUGLAS E ISHERWOOD, 2004) comunica estilos de vida e embute visões de mundo, classificando pessoas e coisas como em um grande sistema totêmico (SAHLINS, 1978; ROCHA, 1985). Como visto, o seriado aborda o relacionamento da diarista com seus patrões a partir de um "viés de classe", apresentando uma contraposição entre dois universos distintos - um marcado pela escassez e outro pela abundância material. A estabilidade dos dois mundos é rompida quando a diarista tenta usufruir de bens e serviços do mundo do "outro" rico. Quando isso acontece, uma série de problemas e catástrofes se sucedem, até que a personagem volte para seu local de origem, sugerindo que a mudança de lugar, nesse contexto, se apresenta como um caminho a ser evitado a todo custo. As diferenças entre pobres e ricos encontram-se naturalizadas e expressas no mundo dos objetos, e o consumo torna-se, assim, o palco das diferenças.

Retornando à questão dos aspectos míticos da narrativa do seriado, foi visto como as relações hierárquicas que estruturam o sistema são reafirmadas ao final. $\mathrm{O}$ mito, segundo Lévi-Strauss (1970), traz sempre uma espécie de "conforto" social ao promover uma resolução de ambiguidades colocadas inicialmente. Paradoxos são assimilados e resolvidos 
por fim, já que o mito contém uma mensagem em prol da tradição. O seriado, como visto, reafirma os lugares de patroa e empregada como universos distintos e complementares, sendo a mudança de lugar encarada como uma disrupção no sistema, que deve logo ser reparada para o retorno à estabilidade inicial. Como o mito tem esse efeito estabilizador, acaba por explicitar o custo da mudança e reforçar um universo marcado por relações hierárquicas.

O seriado expressa algumas questões importantes na dinâmica da sociedade brasileira, no que se refere à possibilidade da mudança, localização de pessoas dentro do tecido social e as relações possíveis entre diferentes segmentos sociais. A possibilidade de se tornar o Outro, no caso, a trajetória do universo da diarista ao da patroa através do consumo, revela um dos pontos críticos da sociedade brasileira. Conforme já sugeriu DaMatta (1994), encontramos em larga escala em nosso contexto um "horror à mobilidade", especialmente no que tange à troca efetiva de posição social. A anulação das diferenças e a possibilidade de mudar de lugar teriam espaço legitimado no carnaval, uma experiência que promove a inversão das relações cotidianas, mas com hora certa para começar e terminar. Em outros momentos, a ideia de mobilidade social seria um ponto crítico e sensível de nossa estrutura social.

Em um estudo anterior (BARROS, 2007), analisei o papel da empregada doméstica como uma importante mediadora na sociedade brasileira. No trabalho em casa de famílias de camadas médias e altas da população, as empregadas têm contato com códigos culturais distintos de seu meio de origem, o que fornece a possibilidade de investigação da dinâmica desse encontro em que regras, hábitos, gostos, estéticas e comportamentos são comunicados e confrontados. A vivência cotidiana com a "intimidade" de uma realidade distinta da sua faz dela uma intérprete privilegiada, que leva e comunica diferentes experiências sociais de um ponto a outro de sua trajetória, tornando-se, assim, uma mediadora entre estilos de vida e experiências sociais diversas.

Na sociedade moderno-contemporânea, o tema da mediação tem grande relevância, por permitir o trânsito e o contato entre universos distintos em um cenário de heterogeneidade sociocultural e diversificação de papéis sociais. Os indivíduos imersos no meio urbano, em especial, estão potencialmente expostos a uma grande diversidade de experiências, por circularem através de universos onde se atualizam valores e visões de mundo distintas e, às vezes, conflitantes, como assinalam Velho e Kuschnir (2001). 
A vida social só existe através das diferenças. São elas que, a partir da interação como processo universal, produzem e possibilitam as trocas, a comunicação e o intercâmbio. O estudo da mediação e, especificamente, dos mediadores permite constatar como se dão as interações entre categorias sociais e níveis culturais distintos. [...] Num contínuo processo de negociação da realidade, escolhas são feitas, tendo como referências sistemas simbólicos, crenças e valores, em torno de interesses e objetivos materiais dos mais variados tipos. A mediação é uma ação social permanente, nem sempre óbvia, que está presente nos mais variados níveis e processos interativos. (VELHO e KUSCHNIR, p. 9-10)

O sistema social brasileiro, em particular, ainda mantém em vários planos uma estrutura hierárquica com muitas gradações e um padrão de dominação de cunho personalista, como já mostrou a análise clássica de DaMatta (1981). Não se está aqui desconsiderando a dinâmica histórica do país, em que as relações sociais marcadas pelo individualismo e pelos princípios universais estão cada vez mais presentes, mas apenas afirmando que uma visão de mundo hierárquica (DUMONT, 1972), ainda é bastante presente em diversos planos sociais. Nesse contexto, mediadores são figuras fundamentais, por facilitarem a comunicação entre as diversas partes do sistema.

O seriado se insere nesse contexto cultural, mostrando uma relação de complementaridade entre patroa e diarista - a primeira oferece salário e eventual proteção, a segunda, além do seu trabalho que contribui para a reprodução social dos ricos, pode servir de ponte para que estes tenham acesso ao universo mágico-religioso popular, que é onde as coisas realmente se resolveriam.

Hamburger (1998) já havia sugerido a ideia de "repertório compartilhado" na experiência televisiva, como um modo privilegiado de diálogo, troca de informações, julgamentos morais e aprendizagem entre telespectadores de diferentes classes sociais. Almeida (2003), por sua vez, mostrou em um estudo como é possível que, através da novela, determinados segmentos sociais tomem conhecimento dos modos de vida de outros grupos, que não teriam acesso de outra forma, promovendo uma espécie de "abertura" para o consumo. O trabalho mencionado (BARROS, 2007) seguiu esta linha de análise, mostrando a importância dos programas de televisão no cotidiano das empregadas, por permitirem uma imersão na sociedade de consumo e um "aprendizado" dos códigos e objetos característicos desta sociedade, em especial, do mundo dos ricos - como eles são e o que eles consomem. Assim, a empregada, ao circular por diferentes universos sociais observa as "novidades" na 
casa da patroa que podem ser vistas também nos conteúdos televisivos - a mídia, nesse sentido, reforça um imaginário referente ao estilo de vida e hábitos de consumo dos mais abastados. "Aprende-se" em primeiro lugar a perceber como os bens são adequados para expressar distinções sociais - produtos aparecem dentro de determinados contextos sociais, sendo consumidos por grupos específicos. Também são apresentados produtos que são reconhecidos como adequados para serem utilizados pela pessoa que assiste ou ainda, são desejados exatamente por pertencerem ao universo de outros segmentos sociais. Ao transitar de volta para seu ambiente familiar, a empregada exerce o papel de mediadora, levando informações sobre este outro mundo, o que não significa uma assimilação passiva, mas sim uma "abertura para o consumo".

Tanto no seriado analisado quanto na pesquisa realizada sobre empregadas, a dimensão do consumo aparece como meio privilegiado de expressão de diferenças sociais. Enquanto a análise da narrativa do seriado aponta para a reafirmação de um universo estável, onde a mudança ocorre para que as coisas voltem ao "seu lugar", uma imersão na experiência de "assistir televisão" junto às empregadas revela que o "repertório compartilhado" (HAMBURGER, 1998) não dilui magicamente barreiras sociais, mas cria um campo de possibilidades de diálogos e "aberturas" para o consumo (BARROS, 2007), o que pode ser entendido como uma relativa aproximação entre mundos distintos.

\section{O "protagonismo" das empregadas: novas representações?}

O seriado A Diarista foi destacado no artigo como um caso exemplar onde a figura da empregada aparece como uma representante de um "velho mundo", imutável e hierárquico, em que eventuais "mudanças de lugar" servem apenas para a reafirmação e retorno a uma ordem natural. Nesse confronto de classes, universos de "pobres" e "ricos" surgem claramente delimitados, com características singulares expressas em um conjunto de hábitos de consumo que cristalizam e tornam palpáveis estilos de vida antagônicos.

Hamburger (2011), em um estudo, argumentou que as novelas no Brasil, nos últimos 40 anos, forneceram diversas interpretações do Brasil, captando, de certo modo, as transformações que se sucederam no país. Assim, as novelas da Rede Globo, a partir de 1969, 
registraram os dramas da urbanização, das diferenças sociais, da fragmentação da família, da liberalização das relações conjugais e dos padrões de consumo. Em 1990, a Manchete propunha a reinterpretação do país centrada na paisagem exótica do "Pantanal", no "coração do Brasil”, enquanto em 2006, a Record apresentava, de modo inédito, o cenário da favela e a ameaça do tráfico no centro da trama da novela Vidas Opostas.

Seguindo essa linha, que pensa "qual teledramaturgia em qual país", finalizo propondo um contraponto entre representações mais tradicionais da figura da empregada doméstica com outras reveladas nas produções mais recentes da TV Globo - as novelas Cheias de Charme e Avenida Brasil. No ano de 2012, a teledramaturgia da maior emissora do país convergiu para a abordagem de temas que giram em torno do emprego doméstico e da ascensão da "classe C" em seus dois horários mais importantes, a saber, a novela das sete e a emblemática novela das oito (ou "das nove", como passou a ser chamada mais recentemente). A presença de membros da "classe C" e de empregadas domésticas como protagonistas das tramas inspirou muitos debates da mídia, em matérias onde se procurava relacionar a ascensão econômica da chamada "nova classe média" com o "novo" papel de destaque na dramaturgia televisiva ${ }^{8}$ na novela das sete, Cheias de charme, o enredo girava em torno de três empregadas que tinham o sonho de formar um grupo musical, enquanto que na novela das oito, Avenida Brasil, a trama central se concentrava na vingança da protagonista (Nina) contra sua antiga madrasta (Carminha), casada com o ex-jogador de futebol Tufão, tendo como cenário o fictício bairro suburbano do Divino.

Sintonizadas com o país que apresenta transformações sócio-econômicas com a ascensão de uma significativa parcela da população a novos patamares de consumo, as duas obras apresentam representações do serviço doméstico que apontam para a possibilidade de mudança e "vingança" social contra humilhações históricas. Vale ressaltar que as empregadas nas duas tramas têm perfis diversos, e algumas se aliam às patroas dominadoras, como é o caso de Socorro em Cheias de Charme e de Zezé, em Avenida Brasil. Além disso, a última novela não deixa de lembrar que os mecanismos de submissão do outro à dominação são exercidos de vários lugares sociais, inclusive pelos próprios subordinados - Janaína, a

8 Matérias como, por exemplo, "A TV se rende à nova classe média". Disponível em http://oglobo.globo.com/revista-da-tv/a-tv-se-rende-nova-classe-media-4934814. Último acesso em 10 ago. 2012 
empregada "boazinha", também tem sua própria empregada, reproduzindo, com um grau mais brando de crueldade, o comportamento arrogante da patroa.

Feita a ressalva, as personagens que movem as estórias - Nina, que apesar de ser uma "falsa" empregada, acaba adotando na sua vingança o ponto de vista das criadas da mansão; e as "empreguetes", que ascendem da condição de subordinadas a estrelas da música, com rituais de inversão em que patroas são transformadas em empregadas - carregam consigo a potência de transformação do universo ao seu redor. A vingança de Nina, no momento mais aguardado da trama - a grande "virada", quando Carminha descobre que ela é na verdade Rita, sua enteada - acaba tomando o tom de uma vingança de classe, para além da questão pessoal ${ }^{9}$. As relações de Carminha e suas empregadas, antes da chegada de Nina, que se emprega na sua casa como cozinheira, remetem a um universo em que a subordinação é total, as diferenças são naturalizadas e a humilhação é a regra.

No momento da vingança, entre os castigos que Nina impõe à Carminha, tem destaque os que envolvem uma inversão de papéis, onde a segunda passa a ser a empregada que tem que obedecer cegamente às vontades da "nova" patroa. Nesse processo de inversão, Carminha é forçada a experimentar as condições precárias da vida das domésticas da casa, sendo "apresentada" ao sabão em pó, tendo que lavar, cozinhar e servir incansavelmente, além de dormir no quarto insalubre com cama desconfortável e comer "macarrão com salsicha", enquanto a "patroa" se delicia com pratos "sofisticados". Nina realiza, assim, uma "vingança de classe", ao submeter Carminha a todas as humilhações que ela costumava fazer com suas empregadas. Para completar o quadro, entre as ordens a serem cumpridas estão ações como promover melhoras no quarto de empregada e dobrar o salário das domésticas da casa.

Os efeitos dessa potência não são unidirecionados, ou seja, não há uma "mudança de lugar" linear em todas as situações da trama. A família de Tufão, por exemplo, é seduzida pelos dotes culinários de Nina, que introduz na casa um cardápio "chique" que se contrapõe ao habitus (BOURDIEU, 1980) alimentar mais popular a que todos estavam acostumados. Ao mesmo tempo em que aderem a um paladar mais "sofisticado", os membros da família, em uníssono, afirmam que preferem morar no Divino do que se mudar para a Zona Sul, apesar de

\footnotetext{
${ }^{9}$ Nina/Rita quer se vingar de todo o sofrimento que Carminha lhe impingiu no passado, quando traiu o seu pai e roubou o dinheiro da família, além de abandoná-la ainda criança no "lixão".
} 
terem condições financeiras para tanto. Valorização do próprio estilo de vida ou proteção contra possíveis humilhações no confronto com a elite da cidade? Embora estes personagens pareçam "confortáveis" onde estão, existe, por outro lado, um forte preconceito de classe em relação à possibilidade de "invasão" da Zona Sul por moradores do subúrbio, simbolizado pela personagem Verônica, que se sente ameaçada com a presença da "nova classe emergente" - e seu perturbador "mau gosto" (BOURDIEU, 1979) - no mítico bairro de Ipanema.

A grande "catarse" vivida através da vingança de Nina parede acenar para a possibilidade de mudança de lugar e para a desnaturalização das relações hierárquicas tradicionais, tão bem representadas, imaginadas e vivenciadas durante muito tempo na figura da empregada doméstica. A vingança pessoal e social de Avenida Brasil e a saga das empregadas de Cheias de Charme tematizam, de certa forma, as ambiguidades de um país que conviveu histórica e culturalmente com um significativo "horror à mobilidade" (DAMATTA, 1981), no que diz respeito à troca efetiva de posição social.

$\mathrm{O}$ imaginário referente à empregada doméstica, muitas vezes articulado à "acomodação das diferenças" vividas no país por conta da dominação personalista que apaziguava os confrontos de classe, parece ter agora novas representações, mais nuançadas por um lado, evidencia-se a vontade de ocupar o lugar do dominador, através do caminho da vingança pessoal e social (Avenida Brasil) ou do exercício de talentos artísticos singulares (Cheias de Charme); por outro, a própria trajetória das ex-empregadas nas referidas tramas e os efeitos da "mudança de lugar" comunicam alguma possibilidade de questionamento da “ordem estável" do antigo mundo.

\section{Referências}

ALMEIDA, Heloísa B. Telenovela, consumo e gênero. Bauru, SP: EDUSC, 2003.

BARROS, Carla. Trocas, hierarquia e mediação: dimensões culturais do consumo em um grupo de empregadas domésticas. Tese de Doutorado. Rio de Janeiro: COPPEAD/UFRJ, 2007.

BORDIEU, Pierre. Le sens pratique. Paris: Minuit, 1980.

La distinction: Critique sociale du jugement. Paris: Minuit, 1979. 
CAMPBELL, Colin. A ética romântica e o espírito do consumismo moderno. Rio de Janeiro: Rocco, 2001

DAMATTA, Roberto. O que faz o brasil, Brasil? Rio de Janeiro: Rocco, $7^{\mathrm{a} e d .,} 1994$.

Carnavais, malandros e heróis: para uma sociologia do dilema brasileiro. $3^{\text {a }}$ ed. Rio de Janeiro: Zahar, 1981.

DOUGLAS, Mary; ISHERWOOD, Baron. O mundo dos bens: para uma antropologia do consumo. Rio de Janeiro: UFRJ, 2004.

DUMONT, Louis. Homo hierarchicus. Paris: Gallimard, 1972.

FREYRE, Gilberto. Casa Grande \& Senzala. Rio de Janeiro: José Olympio, $25^{\text {a }}$ ed., 1987.

GOMES, Laura Graziela. Novela e sociedade no Brasil. Niterói, RJ: EdUFF, 1998.

HAMBURGER, Esther. Telenovelas e interpretações do Brasil. Anais do XX Encontro Nacional da COMPÓS 2011. Porto Alegre, 2011.

Diluindo fronteiras: a televisão e as novelas no cotidiano. In: NOVAES, Fernando A.(dir.); SCHWARCZ, Lilia M. (org.). História da vida privada no Brasil: contrastes da intimidade contemporânea, vol. 4. São Paulo: Companhia das Letras, 1998.

LÉVI-STRAUSS, Claude. O pensamento selvagem. São Paulo: CEN, 1970.

MACHADO, Arlindo; VÉLEZ, Marta Lucia. O quartel das feias. Cadernos de televisão. $\mathrm{N}^{\circ}$ 2, agosto 2008 .

MASLOW, Abraham. Motivation and personality. New York: Harper\&Row, 1954.

MILLER, Daniel. Stuff. Cambridge: Polity Press, 2010.

REZENDE, Claudia B. A empregada na televisão: uma pequena análise sobre representações. In: Cadernos de Antropologia e Imagem, Rio de Janeiro, 5(2), p. 73-89, 1997.

ROCHA, Everardo. Magia e capitalismo. São Paulo: Brasiliense, 1985.

SAHLINS, Marshall. Cultura e razão prática. Rio de Janeiro: Zahar Ed., 1979.

SARTI, Cynthia. A família como espelho: um estudo sobre a moral dos pobres. Campinas, São Paulo: Autores Associados, 1996.

SLATER, Don. Cultura do consumo \& modernidade. São Paulo: Nobel, 2002.

SUAREZ, Maribel; MOTTA, Paulo César; BARROS, Carla. Consumo e castigo: um retrato das relações de consumo no seriado A Diarista. In: ROCHA, Angela; SILVA, Jorge. (orgs) Consumo na base da pirâmide: estudos brasileiros. Rio de Janeiro: Mauad X, 2009.

VELHO, Gilberto; KUSCHNIR, Karina (orgs.). Mediação, cultura e política. Rio de Janeiro: Aeroplano, 2001. 
Original recebido em: 30/10/2012

Aceito para publicação em: 03/12/2012

Resumo sobre o autor:

Carla Barros é professora do Programa de Pós-Graduação em Comunicação (PPGCOM) e do Departamento de Estudos Culturais e Mídia da Universidade Federal Fluminense - UFF. Doutora em Administração pelo Instituto COPPEAD da UFRJ, com estágio de doutoramento-sanduíche no Departamento de Antropologia do University College London, Reino Unido. Especializada em Antropologia Social pelo Museu Nacional da Universidade Federal do Rio de Janeiro - UFRJ e Graduada em Ciências Sociais com concentração em Antropologia Social pela UFRJ. 